Erratum

\title{
Erratum: Responses of Korean Buddhism to the Ethos of Contemporary Korea: Three Discourses in the Wake of Modernization. Religions 10 (2019): 6
}

\author{
Woncheol Yun ${ }^{1, *}$ and Beom Seok Park ${ }^{2}$ \\ 1 Department of Religious Studies, Seoul National University, Seoul 08826, Korea \\ 2 Center for Religious Studies, Seoul National University, Seoul 08826, Korea; vinetar@naver.com \\ * Correspondence: yunwc@snu.kr
}

Received: 9 October 2019; Accepted: 11 October 2019; Published: 17 October 2019

The authors would like to make the following corrections to the paper (Yun and Park 2019):

"Jo, Eunsu" or "Eunsu Jo" referring to the author of two cited works

should be

"Cho, Eunsu" or "Eunsu Cho" respectfully.

The manuscript will be updated and the original will remain online on the article webpage. We would like to apologize for any inconvenience caused.

\section{Reference}

Yun, Woncheol, and Beom Seok Park. 2019. Responses of Korean Buddhism to the Ethos of Contemporary Korea: Three Discourses in the Wake of Modernization. Religions 10: 6. [CrossRef]

(C) 2019 by the authors. Licensee MDPI, Basel, Switzerland. This article is an open access article distributed under the terms and conditions of the Creative Commons Attribution (CC BY) license (http://creativecommons.org/licenses/by/4.0/). 